\title{
About possibility of vibroacoustic diagnostics of electrical discharge machining and characterization of defects
}

\author{
Artur N. Porvatov, Michael P. Kozochkin ${ }^{a}$, Sergei V. Fedorov \\ AND Anna A. OKunkova \\ Moscow State University of Technology "STANKIN", 1 Vadkovsky per., 127994 Moscow GSP-4, Russian Federation
}

Received 24 September 2015, Accepted 15 October 2015

\begin{abstract}
Vibroacoustic diagnostics is one of the most widely spread methods of uninterrupted diagnostics. It is also preferable in the technological processes when there is an absence for optical controlling tools. This paper represents the assets, which are developed for vibroacoustic diagnostics of electrical discharge machining and their experimental approbation.
\end{abstract}

Key words: Electrical discharge machining / vibroacoustic diagnostics / complex geometrically shaped parts / amplitude-frequency response / on-line monitoring

\section{Introduction}

In modern world, the products manufactured by casting are widely used. Casting is the most widespread method. Casting of plastics, nonferrous metals, and other materials into metal molds is performed in this way [1]. Manufacturing of these molds is a complex and laborconsuming process which is hard, and, sometimes, impossible to perform using conventional mechanical treatment methods. Therefore, the use of the processes based on electrical discharge is more and more widespread. When using electrical discharge machining, discharges are performed periodically and in a pulse-like manner, so that dielectric environment (deionized water, emulsions based on mineral oils etc.) between electrodes may restore its electric strength.

The most obvious advantages of electrical discharge method are high processing reliability and precision due to the absence of mechanical loads on the processed workpiece and constant replacement of a tool electrode in the processing area. Each work-piece manufactured according to a certain program can be produced times without number, with a high recurrence rate of the work-piece. The level of precision achieved at advanced foreign electrical discharge machines, equipped with CNCs may reach up to $\pm 80-100 \mathrm{~nm}$.

Examples seem to indicate that, when treating a work-piece using an electric discharge machines, sticking of a non-specialized tool electrode into narrow grooves (for example, when making holes with R0.25 circular

${ }^{a}$ Corresponding author: astra-mp@yandex.ru section with $0.5 \times 1.0$ measurements, and cut height up to $200 \mathrm{~mm}$ ) may lead to the loss of stability and precision of treatment process, short-circuiting, jamming and breaking of the tool electrode, or damaging of diamond dies [2]. These events may cause unsatisfactory cutting quality, defects of the final product, and, sometimes, even damage or failure of the machine.

When treating large work-pieces with the weight up to $300 \mathrm{~kg}$ (in case of separation of two interconnected sections along a complex spatial outline), the process of final undercutting of crosspieces before their separation must be strictly controlled to avoid uncontrollable collapse of inner work-piece into the middle part of the electrical discharge machine. When the screenings or the work-piece itself collapse during the electrical discharge cutting, a special signal sounds, which an experienced operator can distinguish by ear and stop the treatment process in due time, to reinstall bracings of the work-piece, extract it, or use other means of ensuring controlled disjunction of work-pieces and parts.

In order to solve the task of improving the manufacturing precision of a work-piece, first of all, it is necessary to ensure the solution of the above problems of workpiece electrical discharge machining. The main principles of vibroacoustic diagnostics are based on the analysis of the examined object parameters. Vibroacoustic diagnostics solve the tasks of fault detection and assessment of the examined object technical state, in this case - of the tool electrode. Based on the above-mentioned facts it is possible to conclude that the analysis of technological parameters of work-pieces obtained by electrical discharge machining, using vibroacoustic diagnostics process, which 


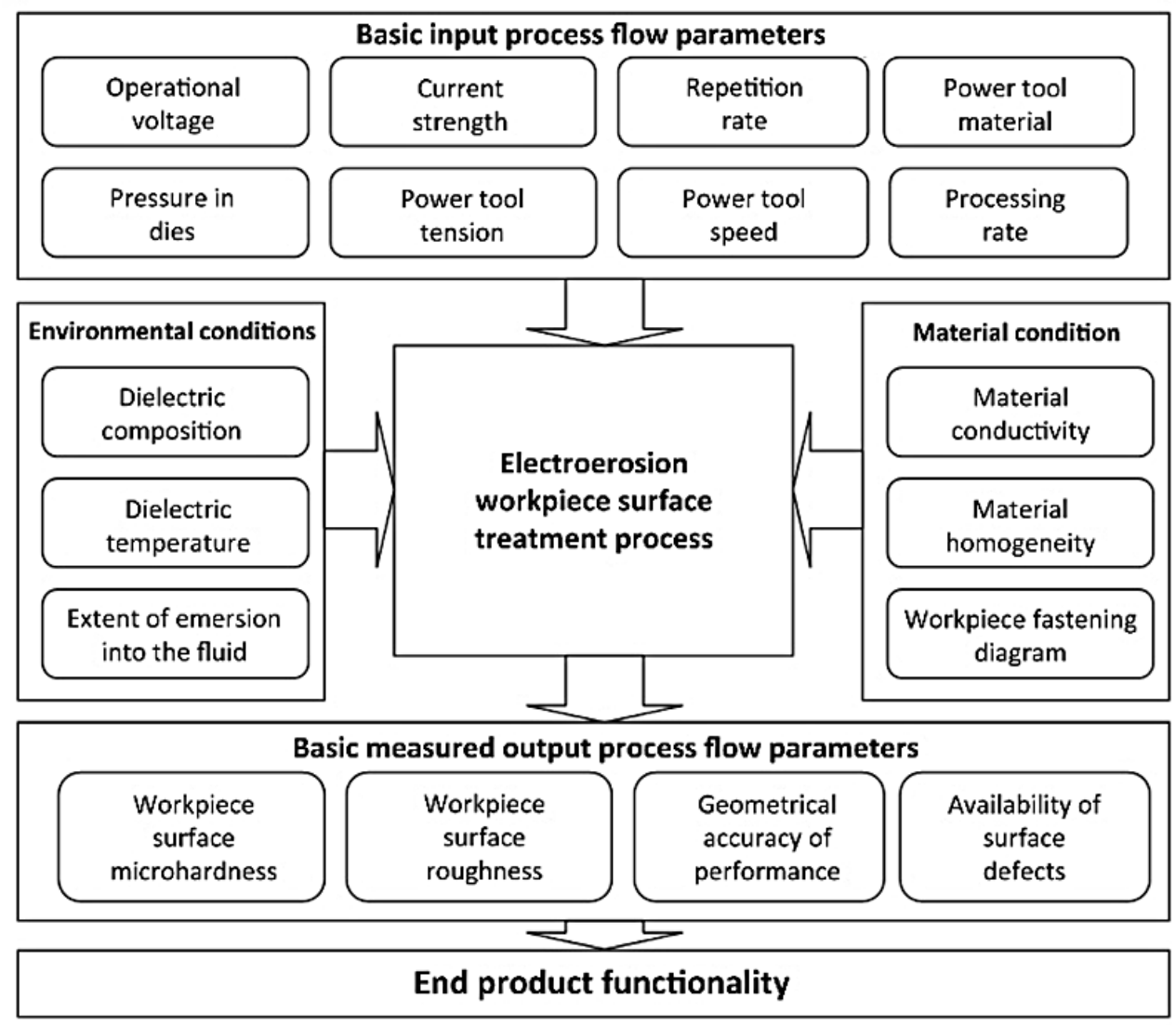

Fig. 1. Functional correlations of input factors and output parameters of the electrical discharge machining process.

consists of information about the oscillatory process and the acoustic signal, is a scientific and technical challenge of current importance.

\section{Task assignments}

There exist approximately 16 initial input factors (conditions), which define the nature of electric discharge processes influencing the quality of work-piece treatment (Fig. 1), as well as the functionality of the final product [3]. The schematic diagram of a course of physical processes during electric discharge treatment is shown in Figure 2 .

The nature of discharge pulse is characterized by such main input factors of the treatment process as voltage in inter-electrode space, electric current, electric pulse frequency (of electric discharge cycle), tool electrode tension, and the pressure of dielectric material in nozzles. It is known that these factors significantly influence treatment stability and, as a consequence, may affect the nature of vibrations during the treatment [4]. It is also necessary to ensure that sensors for measuring vibroacoustic signals are firmly fastened in order to accurately record the information during the treatment.

In order to achieve the current goal, two key factors have been chosen, which then varied to gain the new understanding of the extent of influence of input factors on the nature of vibrations in the process of electrical discharge machining and prior to the collapse of the workpiece screenings: cutting voltage $V_{\mathrm{o}}$ and tension of the tool electrode $W_{\mathrm{t}}$. It was decided to vary these parameters within the following ranges: $V_{\mathrm{o}}-55$ to $65 \mathrm{~V}$ with a $5 \mathrm{~V}$ pitch, $W_{\mathrm{t}}-$ from 30 to $40 \mathrm{~N}$ with a $5 \mathrm{~N}$ pitch (Table 1). 12X18H10T (AISI 321) stainless steel and D16 alluminium alloy (Al-Cu4Mg1) have been used as workpiece materials.

\section{Experiment performance methods}

In order to analyze the technological parameters of products using vibroacoustic diagnostics of electrical discharge machining and to obtain information about the nature of vibrations in the process of work-piece separation during the treatment, the operation of electric discharge cutting has been chosen [5]. During this operation, a long work-piece (with length of the work-piece exceeding cutting width by $5-7$ times) must be placed so that one of its ends is fastened to the working surface of the machine, and its other, longer part freely hangs over the treatment area. Presumably, such fastening scheme can be characterized by high vibration during cutting. For this experiment, two work-pieces from different materials were used: 12X18H10T stainless steel (tool steel for making mold 


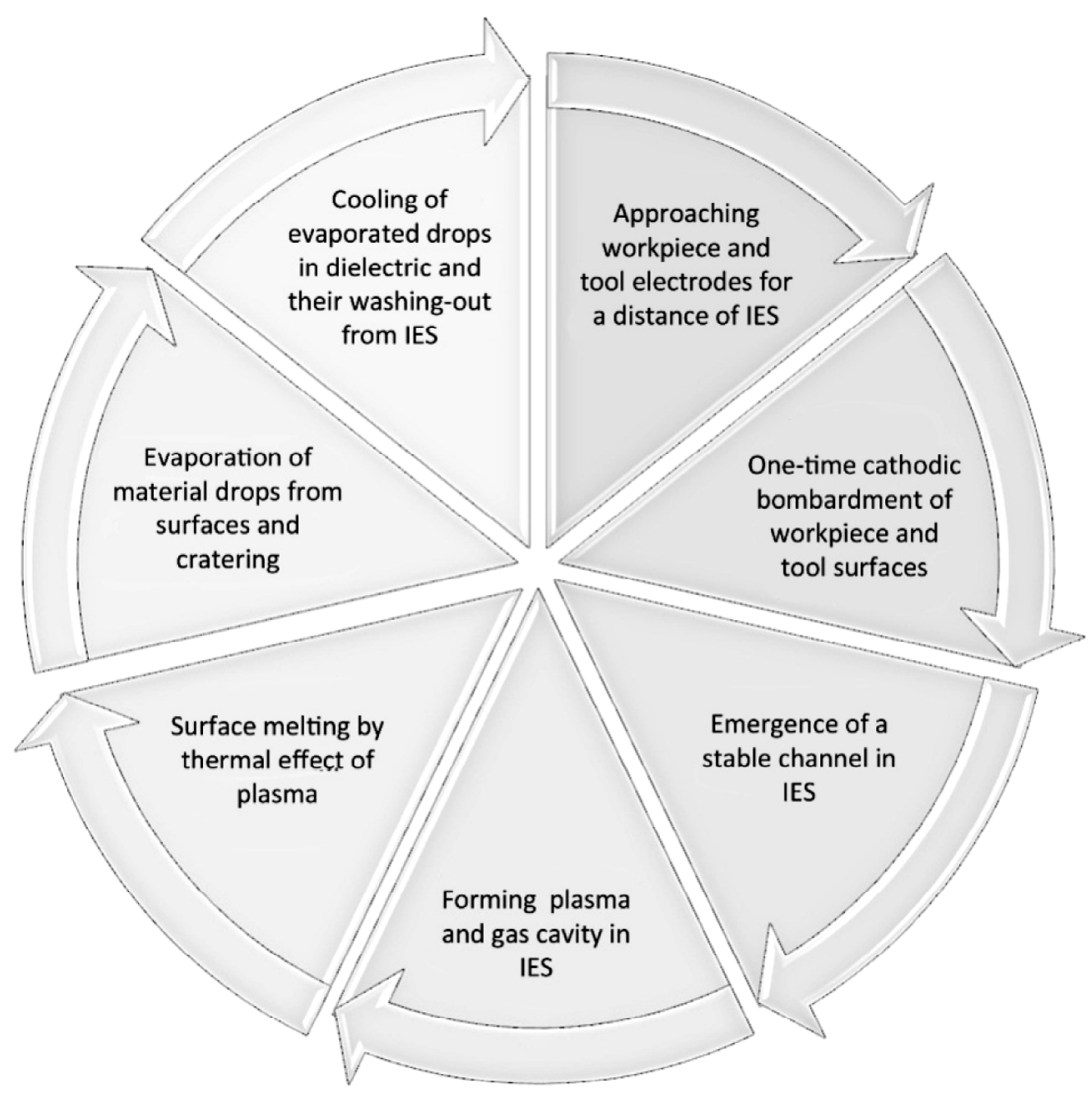

IES - Inter-electrode space

Fig. 2. Depiction of the physical phenomena accompanying the technological process of electrical discharge breakdown, where IES means "inter-electrode space".

Table 1. Experiment performance plan.

\begin{tabular}{ccccccccccc}
\hline Experiment No. & $1 ; 2 ; 3$ & $4 ; 5 ; 6$ & $7 ; 8 ; 9$ & $10 ; 11 ; 12$ & $13 ; 14 ; 15$ & 16 & 17 & 18 & 19 & 20 \\
\hline Material & \multicolumn{1}{c}{$12 \mathrm{X} 18 \mathrm{H} 10 \mathrm{~T}$} & stainless steel & \multicolumn{6}{c}{ D16 aluminum alloy } \\
\hline$V_{\mathrm{o}}(\mathrm{V})$ & 0 & +1 & -1 & 0 & 0 & 0 & +1 & -1 & 0 & 0 \\
$W_{\mathrm{t}}(\mathrm{N})$ & 0 & 0 & 0 & +1 & -1 & 0 & 0 & 0 & +1 & -1 \\
\hline Remarks: 1$)$ & $V_{\mathrm{o}}, \mathrm{V}:$ & $-1-55 ; 0$ & $-60 ;+1-65 ; 2)$ & $W_{\mathrm{t}}, \mathrm{N}:-1$ & $-30 ; 0-35 ;+1-40$. \\
\hline
\end{tabular}

parts, AISI 321) and D16 aluminum alloy (to assess the impact of unit weight on the nature of vibrations during electrical discharge machining) with $200 \times 20 \times 16 \mathrm{~mm}$ dimensions. During treatment, work-pieces with $2 \times 20 \mathrm{~mm}$ and $10 \times 20 \mathrm{~mm}$ dimensions were cut out, without taking spark gap into account, for which a CNC program was prepared in a manual mode.

Work-piece treatment has been performed using the electrical discharge equipment Seibu M-500S (Japan). Brass wire with $0.25 \mathrm{~mm}$ diameter has been used as a tool electrode. Before the end of the cutting procedure, one minute before the collapse of the work-piece, a signal from the accelerometer had been recorded for future analysis [6].

The vibroacoustic signal has been recorded by two accelerometers installed on the working surface for workpiece fastening and on the upper slide of the tool electrode. Such placement has been chosen to control vibrations of both the tool and the work-piece in order to determine the most informative sensor placement.

Work-piece dimensions have been measured using the micrometer Brown and Sharpe (Switzerland), with measuring error of $2 \mu \mathrm{m}$. Samples have been weighed using laboratory scales METTLER TOLEDO (EL104) with measurement range from 0.0001 to $120 \mathrm{~g}$ and the error of 0.0001 g. Experimental sample surface photographs were obtained using Olympus bx51m optic microscope equipped with conoscopic and orthoscopic projection lenses with 10 to 500 times magnification, $5 \times$, $10 \times, 20 \times, 50 \times$ lenses, $12 \mathrm{~V}$ halogen lighting, 90 to $150 \mathrm{~mm}$. working distance. Surface roughness of experimental samples has been measured using the surface waviness recorder/roughness indicator Hommel Tester (Germany). Technical characteristics: measuring range, depending on a used probe, $-8,80,800,8000 \mu \mathrm{m}$ (resolution from 1 to $1000 \mathrm{~nm}$ ); lowest displayed value $0.001 \mu \mathrm{m}$; measuring error $-2 \%$. To obtain the images 


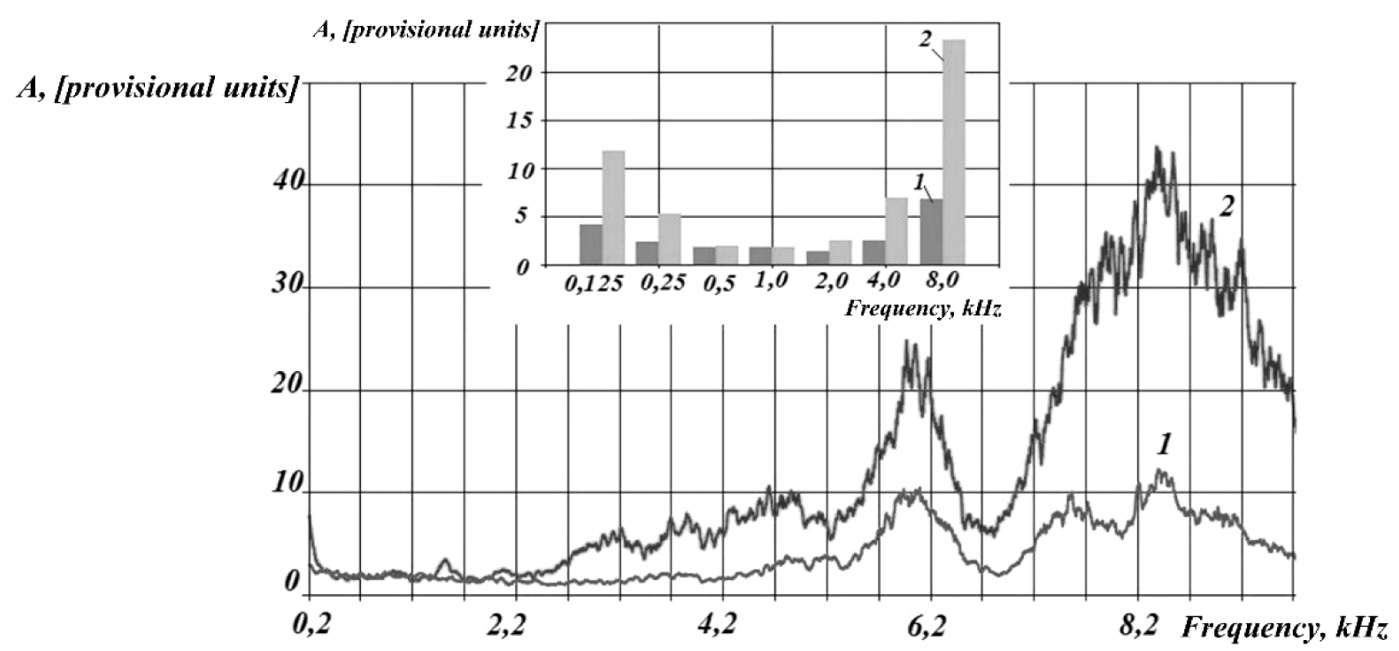

Fig. 3. Low-frequency spectrum vibroacoustic signal: $30 \mathrm{~s}$ before the end of the operation (graph 1) and during the last second of the operation (graph 2).

of the surface of the sample with high spatial resolution, as well as the information about its composition, structure, and properties of near-surface layers, the scanning electronic microscope VEGA 3 LMH (Czech Republic) has been used (magnification up to 1000000 times).

\section{Experiment performance and discussion of the results}

After amplification, signals from the accelerometer have been sent to the ADC and recorded into a computer. Accelerometer signal sampling frequency is $20 \mathrm{kHz}$, which allows performing spectral analysis within the range up to $10 \mathrm{kHz}[7]$.

A work-piece has been positioned manually: a relative coordinate system of the program has been set related to the fastened work-piece by means of a contact of the side surface with a wire in two points.

In the zero position of the program coordinate system relative to the work-piece, the tool electrode has been removed from the work-piece in order to avoid shortcircuiting and to stabilize the treatment process for tool penetration into the work-piece body. The treatment has been performed with full tank of the electrical discharge machine and using preliminary holding of the work-piece in a dielectric material for $10 \mathrm{~min}$ (to avoid further thermal fluctuations of geometric parameters of the workpiece during the treatment)

It has been discovered that fluctuation amplitude surge detected by accelerometers happens during the undercutting of final crosspieces and accompanies the following collapse of the part, which leads to the formation of defects on the treated surfaces (approximately, $10 \mathrm{~s}$. before the end of the treatment). However, the weight and dimensions of the part may influence this parameter. Recording has been done for $60 \mathrm{~s}$. Alterations of the signal coming from the upper slide start $5 \mathrm{~s}$ before the collapse of the part. Vibroacoustic signals have been processed on a computer and presented as octave and amplitude ranges. When the first cuts of the experiment have been performed, it was discovered that the nature of vibrations from the accelerometer installed on the upper slide was more symmetrical than those from the working surface. The symmetry of the vibroacoustic signal is the evidence of the absence of electrical and electromagnetic interference. Herein after, diagnostics have been performed by the signal from the upper accelerometer.

At the end of the treatment, the loss of the process' stability has been observed. During the whole treatment process the vibrosignal has been gradually increasing, then a small surge appeared, then its break, and then another series of surges before the final collapse. This may be the evidence of a gradual decrease in the crosspiece between cut samples and the main body of the fastened work-piece during the treatment, and, therefore, hanging of a larger piece of the material over the treatment area on a thin crosspiece being affected by plastic strain, including that under its own weight. When the sample starts to deform in such a way, it drives the tool electrode to the main body of the work-piece and short-circuit appears, causing burning on adjacent treated surfaces. At this moment, collapse is already imminent. Signal surges by the end of the treatment show the mechanical nature of fractures during work-piece collapse, which consist of a plastic strain and breaking fracture. At this moment, warping of the sample relative to the work-piece appears, accompanied by a series of short-circuits.

Figure 3 shows high-frequency ranges of vibroacoustic signals $30 \mathrm{~s}$ before the end of the operation (graph 1 ) and during the last second (graph 2). It is obvious that in the region of $8 \mathrm{kHz}$ spectral amplitude amplified 4 times. Such alterations of vibroacoustic signal components are sufficient to organize treatment process monitoring, information processing, and to take the respective steps to prevent short-circuits. Excess amplitudes of the vibroacoustic signal show the instability of a spark gap, due to which there is a danger of obtaining low quality of the 
treated surface. This is the basis for the change of manufacturing modes towards the decrease in perturbation of the tool electrode.

It is inconvenient to use too narrow frequency bands to implement vibroacoustic signal amplitude monitoring system, because such a signal may prove to be unstable in case of the change of treatment modes and conditions. It is more convenient to monitor the effective value of the vibroacoustic signal amplitude in a wider frequency range, for example, octave-wide range. Figure 3 shows the octave ranges of vibroacoustic signals $30 \mathrm{~s}$ before the end of the operation and during the last second. For example, in the $8 \mathrm{kHz}$ octave band effective amplitude varies by more than 3 times, and in the $4 \mathrm{kHz}$ - by 2.5 times. Such amplitude variation range is already enough to assess the situation and make a timely decision.

After the samples have been cut, spark gap was measured. As a result of spark gap measuring, conclusions on more appropriate values of technological parameters for finishing electrical discharge machining of samples have been made, which would further decrease material loss, value of the technological spark gap, and ensure a relatively better quality of the treated surface for the single passage, which should, without doubt, positively affect the geometric precision of the final product. Minimal spark gap for stainless steel equals $170 \mu \mathrm{m}$, for aluminum alloy $-196 \mu \mathrm{m}$. Thus, optimal technological treatment factors have been determined.

Vibroacoustic signal recording has been compared to weighing results of the samples and surface waviness record of the treated surfaces.

When registering a vibroacoustic signal $5 \mathrm{~s}$ before the end of the stainless steel part treatment $(\approx 24.5 \mathrm{~g})$ and its collapse $(\approx 4.28 \mathrm{~g})$ a substantial (12 to $15 \%)$ increase of the RMS vibration amplitude value at $8000 \mathrm{~Hz}$ frequency appears during collapse of a large sample, which is definitely due to its heavy weight. When treating an aluminum sample, such tendency is not apparent.

$R a$ roughness, which is a mean value of absolute values (modules) of profile deviations within the set length, has been measured using a surface waviness/roughness recorder. A probe followed the surface of the part from its middle in the direction of the tool electrode movement.

Vibroacoustic signal recording length has been analyzed, totaling $300 \mathrm{~s}$ for stainless steel, which is, approximately, $10 \mathrm{~mm}$ of the work-piece cutting surface (according to chosen treatment modes, where the tool electrode moving speed was determined as $V_{\text {te }}=0.03 \mathrm{~mm} \cdot \mathrm{s}^{-1}$ ), and $150 \mathrm{~s}$ for aluminum alloy, which is also $10 \mathrm{~mm}$ $\left(V_{\mathrm{te}}=0.07 \mathrm{~mm} . \mathrm{s}^{-1}\right)$. Signal vibrations broke $5-6 \mathrm{~s}$ before the end of the treatment, whereas the surface waviness record of the area clearly shows the absence of plastic strains or breaking deformations at this treatment stage. After that, the signal nature was changed for consistently more intensive and irregular, which may indirectly show the beginning of the process of mechanical breakdown of the sample crosspiece: the surface waviness record clearly shows plastical strained area and the area deformed by breaking (Fig. 4).

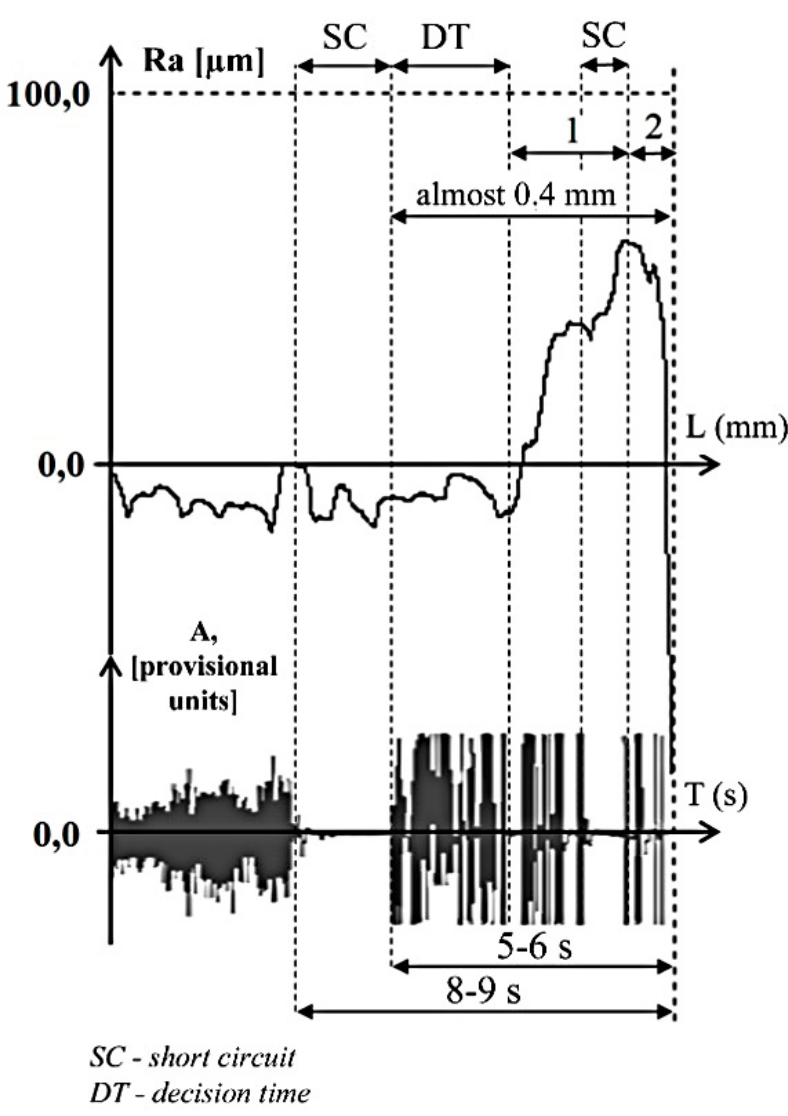

Fig. 4. Surface waviness record of the treated surface of the D16 aluminum alloy sample, and the results of VA signal recording $15 \mathrm{~s}$ before the crosspiece separation, where SC short-circuit areas during the contact of the tool electrode with the sample; DT - decision time; 1 - the plastical strained area of the sample; 2 - the area of the sample fractured by breaking (chipping point).

For illustrative purpose of the demonstration, the surface of aluminum alloy has been chosen, which had clearly visible plastical strained area of the sample before the chipping. The results obtained may be the evidence of the possibility of vibroacoustic diagnostics of electrical discharge machining process in continuous mode, with the possibility to control technological factors of the treatment process (in this case, decision time is approximately $2-4 \mathrm{~s}$ for the samples with 2.0 to $25 \mathrm{~g}$ weight), reducing their values by 15 to $20 \%$ at the moment of vibroacoustic signal surge.

To study experimental samples for defects, photographing of surfaces treated by electrical discharge has been performed using optical microscope. On photography of the surface, two types of defects have been detected based on mechanical impact (chips, burrs) and heat impact (burns, scratches) (Fig. 5).

Additionally, photography of the treated surfaces of the samples using VEGA 3 LMH electron microscope has been performed, which showed that the surface has been flowed and consisted of hardened droplets of melt pool 

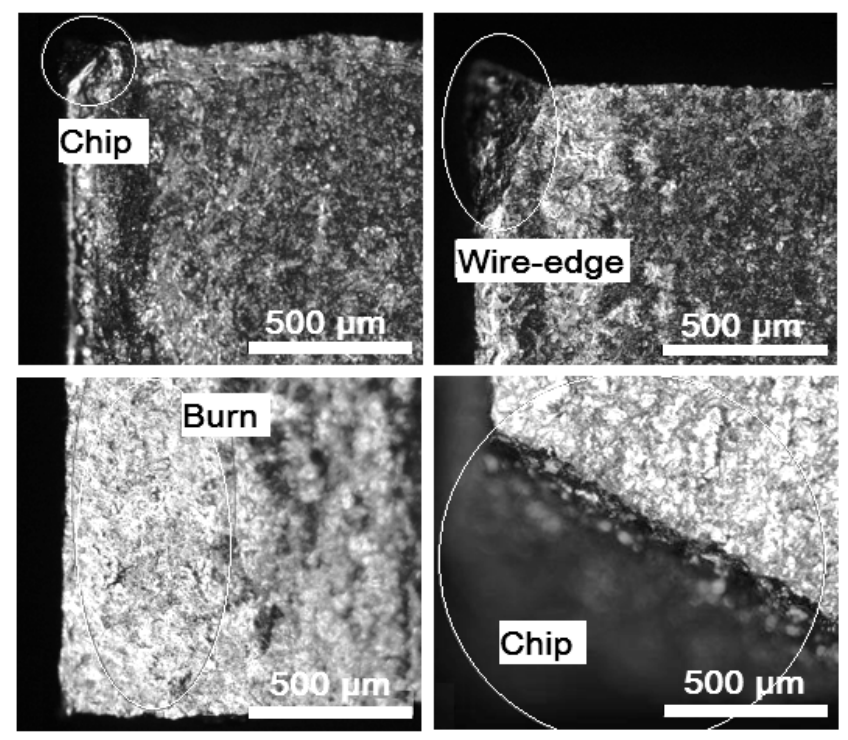

Fig. 5. Surface defects of the parts produced from stainless steel 12X18H10T (AISI 321), obtained by optical microscopy.

\section{Intensity, Imp/s}

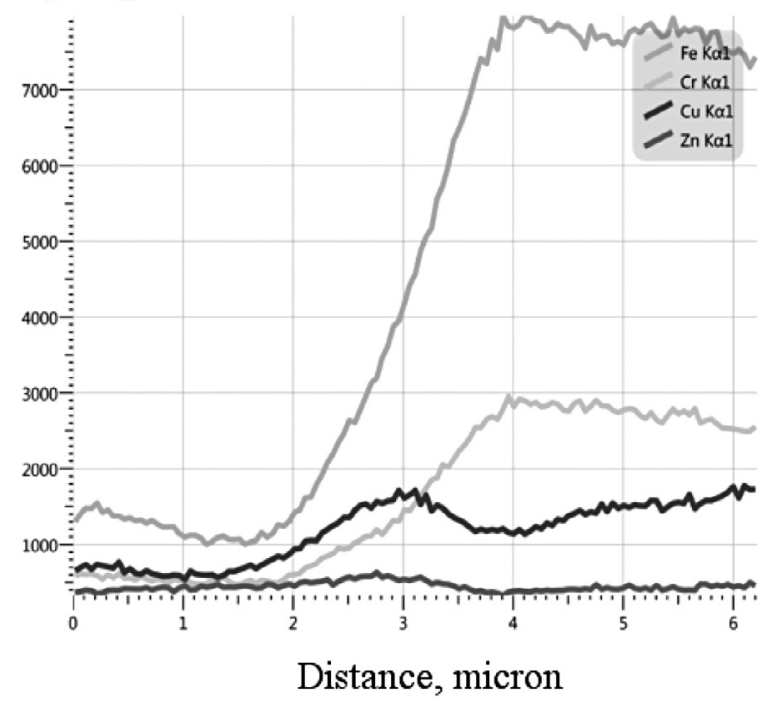

Fig. 6. Distribution of chemical elements on the sample of stainless steel $12 \mathrm{X} 18 \mathrm{H} 10 \mathrm{~T}$, obtained by scanning electronic microscopy.

generated from the impact of a discharge channel during treatment. On the surface of the part made of aluminum alloy, multiple plastic chips of viscous nature can be seen. The analysis of the chemical composition of the cross sections of samples (Fig. 6) has shown that at $4 \mu \mathrm{m}$ distance from the work-piece surface, the depletion of material after electric discharge treatment can be seen. The presence of copper and zinc in the near-surface layer can be explained by the composition of the tool electrode material (brass).

\section{Conclusions}

To solve scientific and technical task of analyzing technological parameters of products obtained using electric discharge treatment, means of vibroacoustic diagnostics of the technological process have been developed. The developed means include a series of instruments connected to the CNC-machine. Preliminary experimental researches show that vibroacoustic diagnostics informatively demonstrate the nature of physical phenomena occurring in the treatment area between the tool electrode and the work-piece.

The octave ranges preferable for continuous diagnostics of the technological process have been revealed. The decision time has been determined for the development of electrical discharge machining adaptive controls to be used in the treatment of critical instrumental-purpose products in order to reduce the negative effects of the technology.

Acknowledgements. The work was performed within the framework of Governmental Regulation of the Russian Federation No. 220 dated 9 April 2010 by contract 14.B25.31.0012, 26 June 2013.

\section{References}

[1] S.N. Grigoriev, V.A. Sinopalnikov, M.V. Tereshin, V.D. Gurin, Control of parameters of the cutting process on the basis of diagnostics of the machine tool and workpiece, Measurement Techniques 55 (2012) 555-558

[2] S.N. Grigoriev, V.D. Gurin, M.A. Volosova, N.Y. Cherkasova, Development of residual cutting tool life prediction algorithm by processing on CNC machine tool, Materialwissenschaft und Werkstofftechnik 44 (2013) 790-796

[3] M.P. Kozochkin, A.N. Porvatov, F.S. Sabirov, Vibration Testing of Technological Processes in Automated Machining Equipment, Measurement Techniques 56 (2014) 1414-1420

[4] M.P. Kozochkin, A.N. Porvatov, Estimation of Uncertainty in Solving Multi-Parameter Diagnostic Problems, Measurement Techniques 58 (2015) 173-178

[5] S.N. Grigoriev, M.P. Kozochkin, F.S. Sabirov, A.A. Kutin, Diagnostic System as Basic for Technological Improvement, Procedia CIRP: 5th CIRP Conference of High Performance Cutting, Vol. 1, 2012, pp. 599-604

[6] F. Zhongtao, Y. Wenyu, W. Xuelin, L. Jurgen, Analytical Modelling of Milling Forces for Helical End Milling Based on a Predictive Machining Theory, Procedia CIRP: 15th CIRP Conference on Modelling of Machining Operations (15th CMMO), Vol. 31, 2015, pp. 258-263

[7] L. Pang, A. Hosseini, H. M. Hussein, I. Deisab, H.A. Kishawy, Application of a new thick zone model to the cutting mechanics during end-milling, Int. J. Mech. Sci. 96-97 (2015) 91-100 